\title{
THE RESEARCH SEARCH FOR THE LEAST BENEFICIAL OVERCAST SKY AND PROGRESS IN DEFINING ITS LUMINANCE GRADATION FUNCTION
}

\author{
R. KITTLER, S. DARULA
}

\begin{abstract}
Recently illuminance levels under ISO/CIE homogeneous standard sky types were characterised in their relative terms after ISO/CIE $(2004,2003)$ standardised as normalised by the luminance in the zenith. Sky luminance and horizontal illuminance based on the gradation and scattering indicatrix functions, including the extreme overcast cases frequently encountered in nature, were recently determined in absolute physical units of luminance in kilocandles per meter square and of illuminance in kilolux. The historical search to find energy and visibility critical sky luminance distributions shows a progression of steps in studying the worst or critical overcast situations. That progression has enabled the determination and evaluation of interior illuminance for comparison of the merits of dual daylighting and artificial lighting under established criteria for comfortable visibility.
\end{abstract}

Keywords: overcast sky, gradation function, daylighting, sky luminance distribution

\section{Introduction}

Since the very early days of the human civilisation when buildings were erected within fortified towns with their inhabitants living in interiors, the problem of daylight illumination was important. The oldest Roman textbook on architectural design by Vitruvius (written in 13 $\mathrm{BC}$ and preserved in manuscripts was printed first in 1487 and now translated to many languages) mentioned the importance of favouring sunlight in urban design and to test for available skylight in interiors. Considering the current and often obstructed views from windows a thoughtful rule was recommended in Book VI, par. VI.6: "From the side where daylight has to be achieved a straight line is to be drawn to the upper rim of the window and if along it is seen an adequate part of the sky above the obstruction, then illumination at this place is undisturbed". This rule probably inherited from old Greek architects, was valid for almost fifteen centuries as it was suited to very frequent atrium and peristyle houses in the Mediterranean climate (Kittler, Kocifaj and Darula, 2012, Figure 2.13). Probably visually pretentious work was placed in Roman houses under the partly or fully roofed atria spaces while interiors with windows seldom faced the exterior or a street (as documented by the bazaar shops in the fraction of the Rome capitol plan or a window in a surgery room in Pompey). Common sense with trust on eyes, the dependency on the visual image (solid angle) of the sky patch and its luminance were realised. The window view from any interior point to the exterior probably

\footnotetext{
${ }^{1}$ Institute of Construction and Architecture, Slovak Academy of Sciences, Dúbravská cesta 9, 84503 Bratislava 45 , Slovak Republic, e-mail: richard.kittler@savba.sk, stanislav.darula@savba.sk
} 
influenced Maurolyco (1575) to characterise the window effectiveness by its uniform luminance within a pyramid with its tip on the illuminated point, which in fact was a trial to define the solid angle extent. The new invention of a subjective luminance meter by Marie (1700) enabled Bouguer (1760) to measure the luminance distribution on a clear sky, but no overcast sky luminance was measured. However, he did not finalise his clear sky luminance data probably due to his busy posts as professor of hydrography at Havre, promotion to the Academy of Sciences in Paris as well as preparing a ten year scientific mission to Peru.

\section{Overcast skies with uniform luminance patterns}

Long before the 18th century the illumination of interiors was dependent only on skylight during daytime. Evenings and night-time illumination was only available from candles and primitive lamps. The traditional uniform overcast sky was accepted by Lambert (1760) who defined the more precise mathematical determination of the window solid angle. After his early lifetime experience in Swiss towns and contemporary optical knowledge he probably considered two main critical daylight situations, i.e. that created by fog or that under dense Stratus cloudiness. The difference between fog and the multiple layers of Stratus clouds is in the altitude of the cloud base. The lowest Status clouds lie a few hundred metres above ground, whereas fog descends to ground level and thus causes very bad visibility conditions. Under stationary synoptic situations the fog as well as Stratus cloudiness with a thickness of $1-1.5$ $\mathrm{km}$ can last for several days during inversion and windless conditions, especially in winter and in valleys. Lambert realised that a uniform unity sky luminance would simplify his illuminance calculations from window apertures when concentrating on the determination of their solid angles. Furthermore, the absolutely diffuse skylight without elevation or azimuth changes presented the best assumption for very diffuse sources as fog (Middleton, 1942) or dense Stratus. The rising cumulation and saturation within Stratus layers full of water vapour, aerosol and water droplets can cause a drizzle. Observing these frequent phenomena and circumstances Lambert $(1760,1773)$ realised that:

- his first theoretical hypothesis assuming a uniform unity sky luminance before 1760 was proven right in 1773 if absolutely diffuse scattering in the homogeneous media are present;

- fog and Stratus thick layers are quite homogeneous with overall and regionally wide extent;

- the cloudiness layers form a dense and diffuse filter that reduce and scatter the original sun beams perfectly and minimise skylight illuminance levels on ground;

- due to uniform sky luminance in any direction, i.e. either in elevation or azimuth as well as in zenith $L_{v Z}$, the resulting integrated horizontal illuminance at ground level $E_{v, d}=\pi L_{v Z}$ or if $L_{v Z}=1, E_{v, d}=\pi$, which is widely known as the Lambertian sky since its definition (Kittler and Darula, 2010);

- a uniform unity sky luminance will simplify illuminance calculations from window apertures when only the determination of their solid angles is needed;

- absolutely diffuse skylight without elevation or azimuth changes presented the best assumption for very diffuse sources as fog (Mie, 1908, Middleton, 1942) or dense Stratus.

Further developments have noticed that the ratio $L_{v Z} / E_{v, d}$ can classify sky types which in the case of a Lambertian overcast sky has the simplest value

$$
L_{v Z} / E_{v, d}=1 / \pi=0.31831
$$


which is independent of solar altitude, i.e. stable within the whole overcast day. Furthermore, taking into account the dependence on the diffuse filtering effect of the dense Stratus cloud multilayer including any turbidity above it, the final reduction can be expressed by the ratio $E_{v, d} / E_{v o, h}$ where $E_{v o, h}=E_{v o} \sin \gamma_{s}$ and $E_{v o}$ is the luminous solar constant (Darula, Kittler and Gueymard, 2005) that can be taken in its average $133.8 \mathrm{klx}$, while $\gamma_{s}$ is the solar altitude, thus

$$
\begin{array}{ll}
L_{v Z}=\left(\frac{E_{v, d}}{E_{v o, h}}\right) \frac{E_{v o}}{\pi} \sin \gamma_{s} & {\left[\mathrm{kcd} . \mathrm{m}^{-2}\right]} \\
\text { If }\left(\frac{E_{v o}}{\pi}\right) \sin \gamma_{s}=42.59 \sin \gamma_{s} \text { then } & L_{v Z}=42.59\left(\frac{E_{v, d}}{E_{v o, h}}\right) \sin \gamma_{s}
\end{array}
$$

After the first five years of regular measurements at the Bratislava station the overcast Lambert sky now after the ISO/CIE /2003, 2004 standard sky type 5/III.1/5777 cases were recorded in 5 minute periods in the range $E_{v, d} / E_{v o, h}$ between roughly $0.05-0.5$ with the mean value 0.219 and mode 0.226 . Taking the typical range $0.1-0.4$ the absolute Lambertian overcast sky luminance values after Eq. (2a) are shown in Figure 1 and after Eq. (3) the resulting horizontal illuminance can be determined as

$$
E_{v, d}=\pi L_{v Z}
$$

with results in Figure 2.

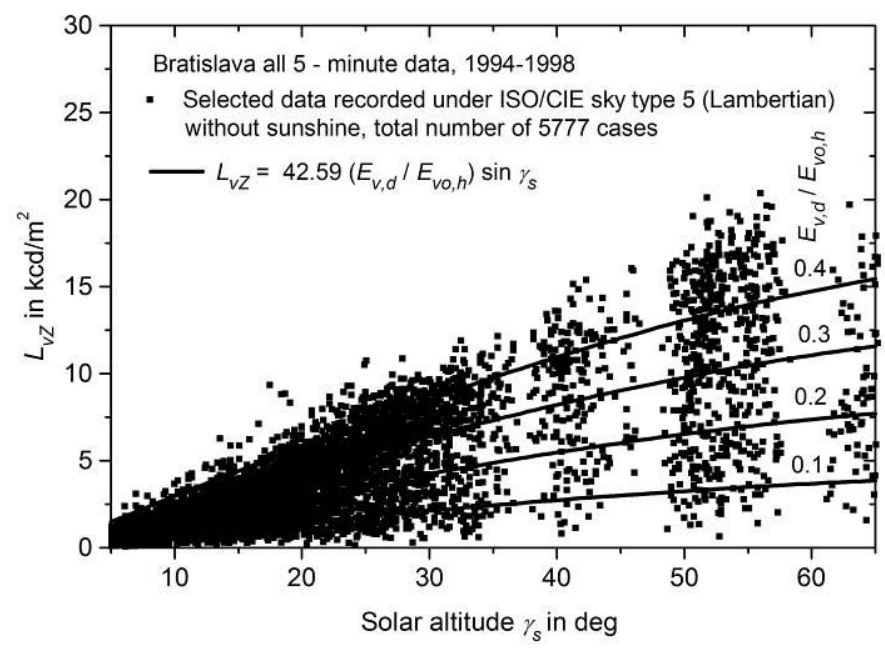

Figure 1. The range of the zenith luminance distributions under overcast sky type 5 


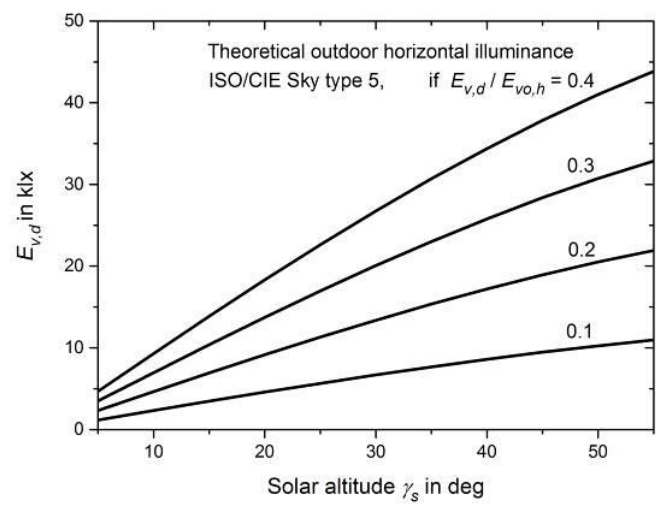

Figure 2. The illuminance levels under oldest Lambertian sky, now ISO/CIE sky type 5

\section{Overcast skies with graded luminance patterns}

The almost two hundred years long acceptance of the basic Lambertian overcast sky type was caused by no experimental data being measured under natural skies due to unavailable precise luminance meters. The original Marie's luminance tube had an undefined acceptance angle and high sky luminances had to be reduced by a set of many glass filters to adjust to a low candle light as a subjective comparable source. Weber (1883) designed and constructed a more sophisticated photometer which originally was to measure exterior illuminance levels. Thus Weber (1885) was the first to start long term daylight measurements in Kiel, Germany from 1890 to approximately 1908 . However, due to tedious and time consuming manipulation with a subjective photometer and the personal attendance needed in daily collection of data, had to be reduced to only one measurement per day at noon time. This meant that all gathered data were measured at daily maximal solar altitudes changing in Kiel (geographical latitude $54.25^{\circ} \mathrm{N}$ ) from $35.75^{\circ}$ on equinox days, while either in winter a gradual drop to $12.30^{\circ}$ had to be expected or a rise up to $59.20^{\circ}$ at noon on the summer solstice day. The Weber's milk-glass photometer was adapted to sky luminance measurements by Kähler (1908) with results in Figure 3.

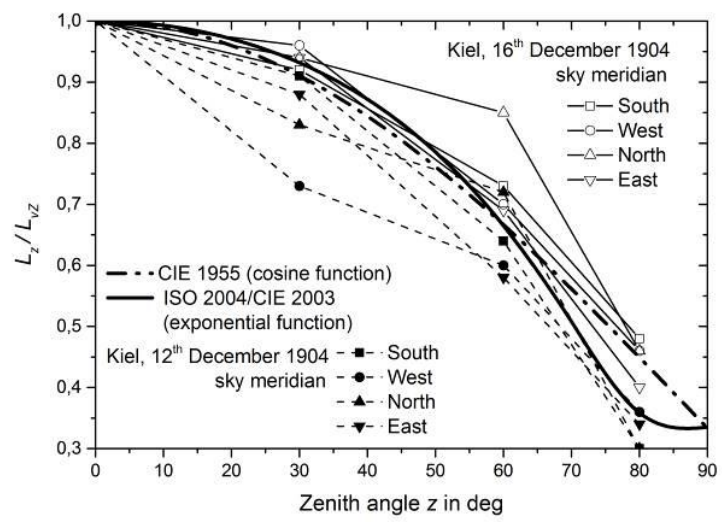

Figure 3. The first subjective luminance measurement results found overcast sky gradations 
Kähler found that the worst overcast skies had no uniform Lambertian sky luminance pattern but a graded luminance from horizon to zenith. His measured gradation under overcast skies is in Table 1 reported in four cardinal directions to test the uniformity in azimuth directions at elevation angles of the sky vault $\varepsilon=2^{\circ}, 10^{\circ}, 30^{\circ}, 60^{\circ}$ and $90^{\circ}$. There instead of $\varepsilon$ the zenith angular distance $z$ is used and compared with his suggested gradation after Eq. (6) and the current exponential ISO/CIE formula. It has to be noted, that his remark was: "Generally it seems that there is no suitable function to be found to express all different gradations of sky luminance under overcast skies" (Kähler, 1908, p. 55). However, the previous page introduced two possible gradations presenting vertical sky luminance changes in dependence on sine of the elevation angles $\varepsilon$, i.e.:

- when the zenith luminance $L_{v Z}$ is twice that the luminance on horizon $L_{v H}$, then it can have the gradation

$$
L_{v Z}=2 L_{v H} \sin \varepsilon
$$

and then he also derived the horizontal illuminance from the whole sky after Lambert's integration is:

$$
E_{v, d}=\frac{5}{3} \pi L_{v H}
$$

- when the zenith luminance $L_{v Z}$ is three times that the luminance on horizon $L_{v H}$, then he proposed the gradation formula for a darker overcast sky

$$
L_{v Z}=L_{v H}(1+2 \sin \varepsilon)
$$

and also the horizontal sky illuminance after Lambert's integration as

$$
E_{v, d}=\frac{7}{3} \pi L_{v H}
$$

For these two sky luminance gradations Kähler suggested possible simple relations between luminance and illuminance under graded overcast skies 2:1 and 3:1, but did not noticed as Lambert the classifying ratio that can be easily derived after Eq. (4) - (7). As under gradation $2: 1$ is $L_{v H}=L_{v Z} / 2$, thus

$$
L_{v Z} / E_{v, d}=\frac{6}{5 \pi}=0.382
$$

or $E_{v, d}=\frac{L_{v Z}}{0.382}=2.618 L_{v Z}$

while under gradation 3:1 is $L_{v H}=L_{v Z} / 3$, thus

$$
\begin{gathered}
L_{v Z} / E_{v, d}=\frac{9}{7 \pi}=0.40926 \\
\text { or } E_{v, d}=\frac{L_{v Z}}{0.40926}=2.4434 L_{v Z}
\end{gathered}
$$


Note, that due to the exponential, instead of sine approximations of gradation functions used in the ISO/CIE sky type set is characterised the gradation for sky type 1 is $3: 1$ and thus $L_{v Z} / E_{v, d}=0.4083$, i.e. almost the same as 0.4093 , but for the gradation $1.5: 1$ and $L_{v Z} / E_{v, d}=0.361$ a different value instead of 0.382 is expected.

Kimball and Hand (1921) also measured the cloudy/overcast sky gradation using an American version of the Weber photometer manufactured by Sharp - Millar calibrated frequently by the U. S. Board of Standards. Their first results (in Table 3, p. 486) were averaged from three days (23rd, 26th and 27th May with solar altitude approximately $40^{\circ}$ ), but were not reliable as these could be influenced by late springtime.

Later measurements published by Kimball and Hand (1922), in Table 2, on page 616 are given averaged values for solar altitudes $20^{\circ}$ (gathered under overcast skies in Washington, and in Chicago, measured on the Federal Building and the University roof) which seemed to be very persuading as shown in Figure 4. All measurement were made on sky meridians at elevations $2^{\circ}, 15^{\circ}, 30^{\circ}, 45^{\circ}, 60^{\circ}, 75^{\circ}$ and $90^{\circ}$ with the azimuth angles of sky meridians $0^{\circ}, 45^{\circ}, 90^{\circ}$, $135^{\circ}$ and $180^{\circ}$ from the solar azimuth.

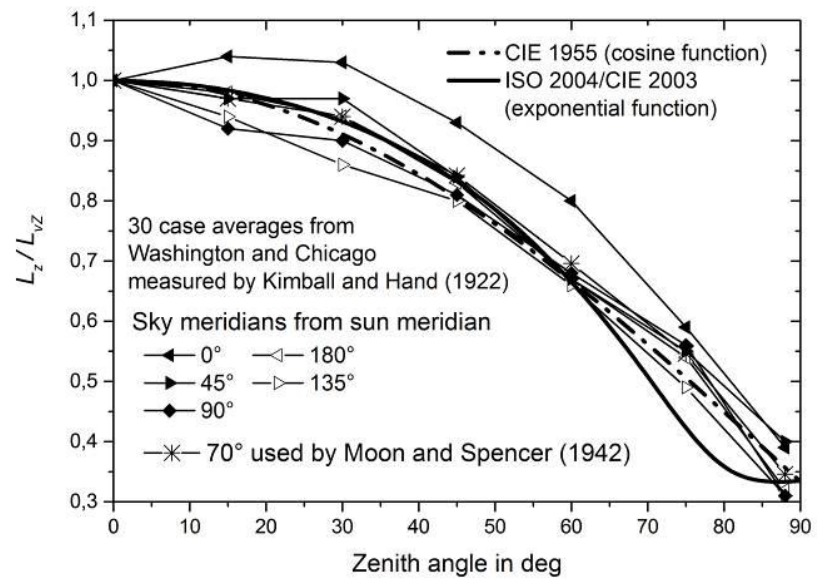

Figure 4. American measurements of overcast sky gradations

While Kähler's sky meridians had N, E, S and W azimuth directions, Moon and Spencer (1942) in their seminal paper utilised Kähler's (1908) without any mention of their sky meridians, Kimball and Hand's (1922) and Kimball (1923) data were given for sky meridians $0^{\circ}, 45^{\circ}, 90^{\circ} 135^{\circ}$ and $180^{\circ}$ as reproduced in the plan orthogonal projection in Figure 5, but in the 1942 paper by Moon and Spencer's the sky meridian $70^{\circ}$ was applied. The final conclusion was internationally accepted as "Moon-Spencer sky" adopted by CIE (1955) standardised the 3:1 gradation for overcast skies in the form dependent on zenith luminance and angular distances of sky elements from zenith $z$ as

$$
\frac{L_{v z}}{L_{v Z}}=\frac{\varphi(z)}{\varphi\left(0^{\circ}\right)}=\frac{1+2 \cos z}{3}
$$




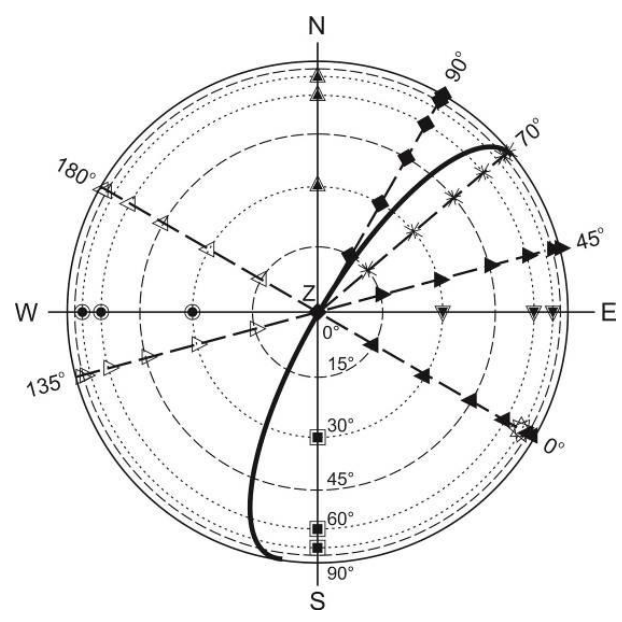

Figure 5. Orthogonal plan projection of the sky hemisphere with measured gradation along different sky meridians

Although the measurements on sky meridians seem to be theoretically right because of the assumed perfect diffusion, now are recommended evaluations of the gradation function for any sky type on the circular section of the sky hemisphere with a radius equal to the zenith distance of the sun to avoid possible scattering indicatrix influences (Kittler, Kocifaj and Darula, 2012, p. 116). When this general evaluation rule for any sky type is accepted for the gradation function then it can be also applied for the overcast skies to measure the gradation trend along the circular section shown by an ellipse in Figure 5. There are also compared different preferred sky meridian choices by Kähler, Kimball and Hand and Moon and Spencer respectively, with the same marks as used in Figures 3 and 4. It is evident that the general system of determining the gradation function on the circular section of the sky hemisphere shows a slower gradation drop along the circular track until reaching the radial width on the solar almucantar. Then a more rapid decrease compared to the cosine gradation is taking place until $8^{\circ}-5^{\circ}$ over the horizon followed by an almost stable level. Of course such a course is difficult to analyse from sky scans with the acceptance angle $10^{\circ}-12^{\circ}$, i.e. when roughly the average luminance on the lowest scan ring $\pm 6^{\circ}$ over horizon is scanned accepting also luminance influences of eventual obstructions (Kobav, Bizjak and Dumortier, 2013, p. 508).

\section{New development of instruments, computers and photographic tools to evaluate sky luminance patterns}

\subsection{Development of photometers}

Since the first subjective luminance meter constructed in 1700 by Marie and used extensively by Bouguer considerable improvements on subjective photometers were accomplished, especially in the last years of the 19th century, e.g.:

- Applying the Lumer-Brodhun (1889) photometer head enabled to adjust a better equality of two luminance images when comparing two particular luminances by subjective observers;

- The artificial source as a comparison standard was gradually replacing a candle by the gas lamp, Hefner-Alteneck (1891) lamp or a small tungsten incandescent lamp as well as later by various electric lamps (Fleming, 1903); 
- new double purpose objective photometers to measure either illuminance or luminance were industrially produced and calibrated.

The discovery of electric light sources and photocells with adjustments of cosine corrections and adaption to human visual $V(\lambda)$ sensitivity by yellow-green filters enabled in the 20th Century the production of objective photometers, i.e.:

- Industrial production of portable and laboratory illuminance meters, e.g. current portable Krochmann PRC RadioLux 11 and LMT Pocket Lux 2 or precise PRC PhotometerRadiometer 111;

- Development of luminance meters with several acceptance angles, e.g. Konica Minolta luminance meter LS-100 with a very small $1^{\circ}$ acceptance angle;

- Applying small server step motors new luminance scanning meters were available after 1990 made in reduced series, e.g. American scan meter by Pacific Northwest Laboratory, German PRC Krochmann scanner or Japanese EKO scanner, all with acceptance angles $10^{\circ}-12^{\circ}$, which all collect and archive data in personal computer files. The original proposal by Tregenza (1987) suggesting for sky scanner the subdivision of the sky hemisphere into 151 circular elements roughly representing an angular subtending to $\pi / 15$ radians which is $12^{\circ}$. However, the Krochman and EKO scanners are constructed for reading luminance values in 145 sky elements after the recommendation by CIE (1994).

\subsection{Developments in photography to reproduce whole sky images}

The optical registration and reproduction of pictures on light sensitive materials were experimentally tried at the start of the 19th century. It took roughly 80 years of development to start with cameras using rollable films and another 55 years to produce more sophisticated cameras to take pictures on colour or negative colour films. Then photos of the whole sky could be taken on paraboloidal mirrors placed horizontally under the camera as by the Pleijel's globoscope (1952) or using the concave lens for the whole sky photos (Hill, 1924, discussed by Longmore, 1964) and by Ogiso and Takei (1966) with orthographic projection lens and fish-eye camera. Another solution was to mount stereographic fish-eye lens directly on the camera, as with the Nikon film camera which was sold with such adjustment from 1980, and even more sophisticated is a digital camera which could send the image directly into computer files, e.g. current Nikon with Sigma circular fish eye lens F2.8 EXDC with an equisolid projection, both in Figure 6.

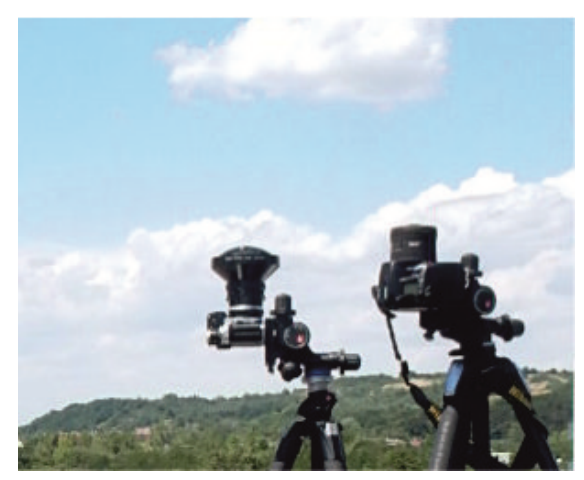

Figure 6. Nikon film and a digital camera with different fish-eye lenses 
The older fish-eye photos were previously used together with radiance scanning to document the cloud type, cover or placement of clouds, e.g. by Valko (1986) during his measuring campaigns in Switzerland, Austria or Spain. Current digital computer specification is capable of calibration in luminance units, e.g. kcd.m-2, to determine the whole sky luminance pattern in its fluent or abrupt distribution either in reality or simulated within artificial skies (Baxant, 2005; Kobav, 2006; Sumec et al., 2013).

\subsection{The worldwide unification of units and standards and application of scientific and technology innovations}

The significant milestone to differentiate photometry from radiometry was started with the discovery of the human eye spectral sensitivity, i.e. $V(\lambda)$ function by Konnig (1891) and thus the specification of photometric units. However, these units especially for luminance and illuminance were influenced by the traditional length units used in different countries. Such as in France before the French Revolution the unit was "toise" (circa $1.949 \mathrm{~m}$ ) used by Bouguer which was deduced from the width of the King's gate to Louver while from the 7th April 1795 the law introduced as a basic length unit a "metre" representing the one tenth millionth distance from the North pole to Equator. In Britain/U.K. or U.S.A. feet were favoured, older length units (a foot $=0.3048 \mathrm{~m}=30.48 \mathrm{~cm}$ ) and thus illumination was measured in foot-candles equal to $\mathrm{lm} / \mathrm{sq} . \mathrm{ft}$. $=10.764 \mathrm{~cd} . \mathrm{m}^{-2} . \mathrm{lm} / \mathrm{sq}$.ft. could to be recalculated to $\mathrm{m}^{-2}$ therefore it is $10.764 \mathrm{lux}$. In case of luminance even a higher number of interrelations were used. Similar units linked to different $\mathrm{cd}$ or $\mathrm{lm}$ based units were applied. In Britain/U.K or in the U.S.A cd/sq.f. $=10.764$ metrostilb $=10.764 \mathrm{~cd} . \mathrm{m}^{-2}$, while in Europe the unit $\mathrm{cd} / \mathrm{m}^{2}$ was named in some countries as a stilb, a metrostilb, or a nit, but when the $1 \mathrm{~m} . \mathrm{cm}^{-2}$ was taken as a basis then it had the name a Lambert or an apostilb if in $1 \mathrm{~m} . \mathrm{m}^{-2}$. This was made even more complicated by the preference of the Hefner-Alteneck candle as a unit of luminous intensity in Germany inspired Blondel (1896) to hurry with his proposal of an international agreement on optometric units. It was based on the newly defined candela and light flux in a narrow solid angle of a steradian in lumens, thus luminance had a cd. $\mathrm{m}^{-2}$ unit and illuminance $1 \mathrm{~m} . \mathrm{m}^{-2}$ unit named lux. This proposal was favoured by the electrical engineers congress and accepted by standardisation institutions in Washington, Paris and Berlin. However, in Britain and the U.S.A. still old foot-candles were preferred until the SI unit system was standardised in 1960.

After the establishment of the Committee International de 1'Éclairage (CIE) many international standards were defined as the $V(\lambda)$ spectral curve, the Moon-Spencer Sky was adopted by CIE (1955) and finally the ISO/CIE 15 sky type set (2003/2004) that all include the overcast sky patterns.

The CIE initiative to start local regular recording of outdoor illuminance level and simultaneous zenith luminance in minute intervals within (International Daylight Measuring Programme) helped to determine the frequency and occurrence of the worst overcast skies yearround in long terms. In absence of any photometric measurements by the international network of meteorological stations, these are data of the daylight climate recorded worldwide. 


\section{New possibilities and measured data to be utilised in defining sky patterns}

\subsection{Sky scan data available for deriving gradation trends on overcast skies}

The first zenith luminance distributions measured in San Francisco by Karayel (1984) were followed by sky scan regular recordings from June 1985 to December 1995 within the LBL project with roughly 16000 all sky scans. Such a great number of scan data stored in LBL computers could never be published and therefore nobody could evaluate them thoroughly. Fortunately, Dr. Richard Perez, as a partner in the U. S. - Slovak grant project, had the possibility to select 88 typical scans, these could be analysed and their gradation and scattering indicatrix functions could be used to form a set of quasi-homogeneous sky types for the ISO/CIE standard (Kittler, Darula and Perez, 1998). However, due to the subtropical daylight climate in California, dense overcast sky scans measured during the June 1985 to December 1995 period were missing. Later, neither few sky scans from Sydney, Australia (Hayman, 1992) nor more scan data from Tokyo (Igawa, 1992) contained graded overcast sky patterns from which gradation functions could be analysed.

To check the importance of graded overcast skies served the regular measurements of zenith luminance and horizontal outdoor illuminance data recorded at the general stations. According to Bratislava IDMP data collected during five years $1994-1998$, the selected number of cases within the $L_{v Z} / E_{v, d}=0.4083 \pm 2.5 \%$ range totalled 9716 cases in 5 minute periods (Darula and Kittler 2004), i.e. quite frequent situations especially in wintertime (Kittler, Kocifaj and Darula, 2012, p. 179).

All the oldest gradation measurements were following the vertical sky meridian elevation angles in different azimuth positions:

- Kähler chose the cardinal point directions (Figure 5) without respect to the sun meridian which was due to the morning solar altitude around $18^{\circ}-20^{\circ}$, i.e. roughly in azimuth directions $118^{\circ}-120^{\circ}$ from North;

- Kimball and Hand also preferred the solar altitude $20^{\circ}$ for measurements of overcast sky gradations, but their chosen sky meridians as shown in Figure 5 were taken from the sun meridian following either one or both sides of the sky vault;

- Moon and Spencer had no measurements of their own during the wartime study and so used Kähler's and particularly Kimbal and Hand's data for the $70^{\circ}$ sky meridian taken from sun azimuth shown by star symbols in Figure 5. It is evident that the choice of $70^{\circ}$ sky meridian is quite close to the ellipse track where the gradation can be determined more precisely for all sky types.

It is evident from Figures 3 and 4 that the gradation trends were rather inconsistent, while theoretically equal gradation drops were expected in all sky meridians, even when probable atmospheric non-homogeneity some irregularity seemed to be possible.

Recent general sky gradation studies utilised already scanned data, following a special net, so no precise sky luminance recording along the circular sky hemisphere section is directly available, therefore, only interpolated values from scan results have to be calculated. In Figure 5 the ellipse curve representing this circular section in the plan due to the distortion in orthogonal projection of the sky hemisphere is drawn. Using sky scans Kobav (2006) analysed also overcast sky gradations. Hopefully, in the future more studies are expected to measure directly relative gradation and indicatrix functions either following circular tracks by luminance meters with narrow acceptance angles or reading luminance values along these tracks from fish-eye photos. 
Unfortunately, no reliable measured luminance values on dense overcast sky were available at the end of the 20th Century. For the set of 15 ISO/CIE sky types the generally valid representation of the gradation function after the exponential function and for the dense overcast sky type was taken in accordance with the best fit after Eq. (10) and documented in Figures 3 6.

\subsection{Determination of the overcast sky conditions under ISO/CIE sky type 1}

The introduction and determination of the gradation functions (Kittler, Darula and Perez, 1997) and their adoption by CIE (2003) and ISO (2004) for 15 homogeneous sky types was the first step made for defining the set of sky types from dark overcast to cloudless clear skies in relative terms after the basic Eq. (11)

$$
\frac{L_{\chi z}}{L_{v Z}}=\frac{f(\chi) \varphi(z)}{f\left(Z_{s}\right) \varphi\left(0^{\circ}\right)}
$$

The further break through to determine these relative sky patterns in absolute physical units together with their effect on resulting exterior horizontal illuminance levels under free sky horizon was solved thanks to the large sample set of sky scanned measurements collected by LBL and made available for evaluation within the Slovak - U.S.A. grant project (Kittler, Darula and Perez, 1997). Another main success was in finding the luminance-illuminance classifying ratio $L_{v Z} / E_{v, d}$ produced by the integration for all fifteen ISO/CIE sky types as well as determining the simplified precise best-fit general formula valid in the range of solar altitudes $0^{\circ}-70^{\circ}$ : Under the overcast and very cloudy skies without any sunlight the zenith luminance is influenced by the ratio of the transmitted horizontal illuminance to the simultaneous extraterrestrial horizontal illuminance level, i.e.:

$$
L_{v Z}=Y\left(E_{v, d} / E_{v o, h}\right) \quad\left[\mathrm{kcd} \cdot \mathrm{m}^{-2}\right]
$$

If sunlight is absent the $E_{v, d} / E_{v o, h}$ ratio is relatively stable during the sky type existence and it has to be noted that under sky types 1 is $Y=\mathrm{B} \sin \gamma_{s}=54.63 \sin \gamma_{s}$ graphically represented in Figure 7 where zenith luminance is dependent on solar altitude.

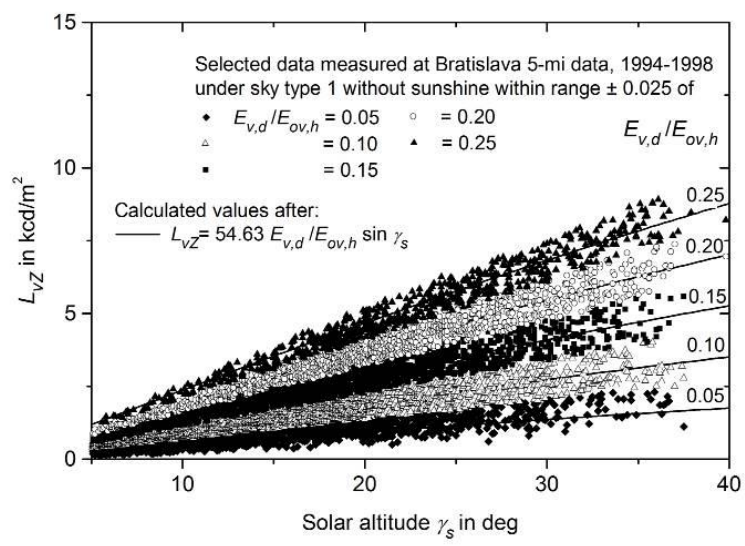

Figure 7. Zenith luminance under overcast ISO/CIE sky type 1 


\section{Horizontal illuminance under the extreme overcast ISO/CIE sky type 1 and its dependence on the sky luminance pattern}

Once zenith luminance is known in absolute physical units, i.e. $L_{v Z}$ in $\mathrm{kcd} \mathrm{m}^{-2}$ or $\mathrm{cd} \mathrm{m}^{-2}$, (Kittler and Darula, 2015), then the ISO/CIE relative distribution patterns also absolutely true physically defined luminance patterns on the whole sky vault can be specified. While under the sky types 1 , or 3 the luminance isolines follow circular rings indicating that in all azimuth directions the sky luminance is the same and only the gradation tendency is represented by their spacing in the case of the Lambertian sky type 5 there are no isolines because all over the sky vault there is the same luminance equal to $L_{v Z}$.

Under the sunless overcast sky type 1 its zenith luminance is dependent on the invisible solar position/altitude as well as determined by the basic filtering/transmission ratio of the whole atmosphere $E_{v, d} / E_{v o, h}$. The ratio $L_{v Z} / E_{v, d}=0.4083$ defines the horizontal illuminance level, i.e. $E_{v, d}=\frac{L_{v Z}}{0.4083}=2.4492 L_{v Z}$ or using Eq. (9) and the ratio $E_{v, d} / E_{v o, h}$ is

$$
E_{v, d}=2.4492 \frac{E_{v, d}}{E_{v o, h}} 54.63 \sin \gamma_{s}=133.8 \frac{E_{v, d}}{E_{v o, h}} \sin \gamma_{s}
$$

When the ratio $E_{v, d} / E_{v o, h}$ is measured or standardised for the minimal overcast sky type 1, e.g. $E_{v, d} / E_{v o, h}=0.1$ then $E_{v, d}$ follows the sine curve $E_{v, d}=13.38 \sin \gamma_{s}$ during such an overcast day.

Earlier previously analysed extreme days of 11 th November 1995 with $E_{v, d} / E_{v o, h}=0.1-$ 0.2 and with the extreme lower range of $0.04-0.07$ measured on 25th November 1995 were documented (Kittler et al, 2012, Figure 3.11). In recent IDMP Bratislava measurement data indentified a perfect overcast case on February 19th 2010 at 9:44 (solar altitude $21.18^{\circ}$ ) when also a fish-eye camera image was taken (Figure 8a). This Stratus fully overcast sky was additionally dispersed by a low inverse fog layer with the ratio $E_{v, d} / E_{v o, h}=0.095$.

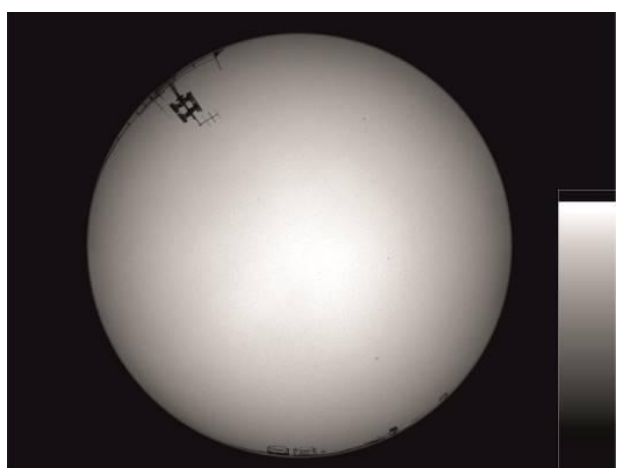

a.

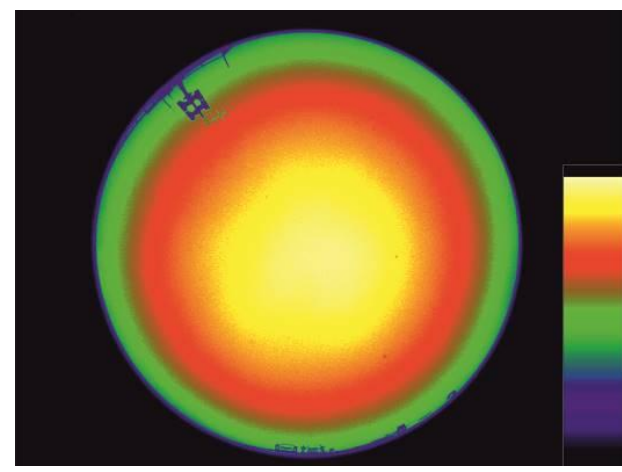

b.

Figure 8. Fisheye image of the overcast sky taken on February 19th, 2010 in Bratislava with relative luminance maps in appropriate scales 
The photographic image in Figure 8a and even more subjectively the intensity colour map in Figure $8 \mathrm{~b}$ show an absolutely symmetric sky pattern with the perfect overcast sky gradation. Furthermore the colours highlight the "green" circular strip close to horizon which indicates an almost luminance constant region corresponding to the gradation function formula. Unfortunately, when the 2010 shot was produced in JPEG format the equisolid projection of the fish-eye lens was not yet calibrated and the luminance pattern image was uncertain and needs the picture in the original undistorted NEF format for the objective luminance transformation. Thus the chance of the precise mathematical definition of the gradation function for the ISO/CIE sky type 1 is still unsettled although the general exponential ratio function seems to be closer to reality than the cosine and is applicable for all sky types including cloudy and cloudless skies.

In the case of dense and dark overcast skies the enormous rise of the relative air mass towards the horizon although compensated by some ground reflection might cause a relatively even ring of dark sky luminance around horizon as shown by some fish-eye images taken in Bratislava. Recently an interesting photo taken by Fredericks, (2015, p.130) on the vast horizontal ice sheet in Greenland presents an example of a dark luminance ring above the horizon even not reduced by the extremely white ice and snow reflectance of the flat ground surface (Photo ICESHEET 2426). With respect to copyright restrictions it is not possible to reproduce this photo, but under overcast conditions is evident a darker strip exists around the horizon with almost a constant sky luminance reaching the elevation about $10^{\circ}-12^{\circ}$, i.e. similar to the exponential CIE gradation curve.

\section{Conclusions}

The historical search and trials to mathematically define inter-relations occurring under the worst winter overcast skies, i.e. relations among zenith luminance, sky luminance pattern and outdoor diffuse horizontal illuminance levels as a filtered part of the virtual simultaneous extraterrestrial horizontal illuminance level, have shown a gradual progress including:

- the assumption of the absolutely diffuse scattering of extraterrestrial sun beams and their penetration as diffuse sky light through the atmosphere layers of fog and/or Stratus clouds;

- the assumption of a unity luminance on the sky hemisphere as well as the unity value of the relative scattering indicatrix function in the whole atmospheric medium - Lambertian sky;

- the definition of the Luminous Solar Constant average $E_{v o}=133.8 \mathrm{klx}$ with possible $\pm 3.3 \%$ deviations when a specific date within a year is to be taken into account or really measured;

- the acceptance of the worst graded overcast sky luminance pattern, now standardised as the sky type 1 by CIE (2003) and ISO(2004);

- the specification of a standard relative luminance gradation of the sky type 1 expressed by an exponential formula after Eq. (10);

- the determination of the stable value of the classification ratio $L_{v Z} / E_{v, d}=0.408$ for all solar altitudes for ISO/CIE sky type 1;

- the ISO/CIE sky type 1 is considered to represent the worst wintertime graded overcast sky when the most frequent $E_{v, d} / E_{v o, h}=0.1$ and $L_{v Z}=5.463 \sin \gamma_{s}$ in kcd.m ${ }^{-2}$ shown in Figure 7;

- the minimal outdoor diffuse horizontal illuminance under a free horizon of the worst dense overcast sky is defined after the ratio $E_{v, d} / E_{v o, h}$ and it seems that that the ratio 0.1 can be 
taken as minimum for daylight design purposes, thus as shown in Figure 8 is $E_{v, d}=2.4492$ $L_{v Z}$ in klx.

These conditions determine in accordance with the ISO/CIE standard the theoretically worst densely overcast sky in winter is the sky type 1 with full absence of direct sunlight and an absolutely fluent and graded luminance pattern either in relative terms or absolute physical units resulting in the exterior horizontal illuminance dependent on momentary solar altitude or defined date and true solar time in hours.

\section{Acknowledgement}

This study was done under the Slovak Research Grant APVV 0118-12 and VEGA 2/0117/14 and the gratitude for this support is expressed.

\section{References}

[1] Baxant, P. (2005), Common digital photography and its calibration to luminance measurement. Proc. Lux Europa Conf., Berlin. Deutsche Lichttrechn. Ges., 318-321.

[2] Bouguer, P. (1760), Traité d'Optique sur la gradation de la lumiére. Paris: Guerin et Delatour. (Latin translation Bougeri Optice de Diversis Luminis Gradibus Dimetiendis by Richtenburg J., Vienna-Prague, 1762. Russian translation Opticheskiy traktat o gradaciyi sveta, edited and commented by A. A. Gershun, Moscow: Izd. Akad. Nauk. SSSR, 1950. English translation by Knowles Middleton W. E.: Pierre Bouguer's optical treatise on the gradation of light. Toronto: University of Toronto Press, 1961).

[3] Commission Internationale de l'Éclairage. (1955). Natural Daylight, Official Recommendation. Compte Rendu CIE 13, Session, 2, part 3.2, p. 2-4, Central Bureau CIE, Paris.

[4] Commission Internationale de 1'Éclairage. (1994). Guide to recommended practice of daylight measurements. Technical Report CIE 108-1994. CB CIE Vienna.

[5] Commission Internationale de 1'Éclairage. (2003), Spatial distribution of daylight - CIE Standard of General Sky. 2003 CIE Standard S 011/E: 2003, CB CIE Vienna.

[6] Darula, S. and Kittler, R. (2004), New trends in daylight theory based on the new ISO/CIE Sky Standard: 1. Zenith luminance on overcast skies. Build. Res. Journ., 52, 3:181-197.

[7] Darula, S., Kittler, R. and Gueymard, Ch. (2005), Reference luminous solar constant and solar luminance for illuminance calculations. Solar Energy, 79, 559-565.

[8] Dumortier, D. and Vetro P. (2001), Luminance calibration of the Nikon Coolpix 950 digital camera. Proc. Lux Europa Conf., 341-345.

[9] Fleming, J. A. (1903), the Photometry of electric lamps. Journ. of Proc. of Institute of Electric Engineers, 32, part 159.

[10] Frederiks, M. (2015), End of the Earth. National Geographic, 227, 3, 122-130.

[11] Hayman, S. (1992), Luminance scans, global and diffuse illuminance data measured in Sydney - Mascot, 9th - 22 June. Private communication.

[12] Hill, R. (1924), A lens for whole sky photographs. Quarterly Journ. of Roy. Met. Soc., 50, 227-235. 
The research search for the least beneficial overcast sky and progress in defining its luminance gradation function

[13] Hefner von Alteneck, J. (1891), Über das Verhalten von verubreinigtem Brennstoff in der Amylazetatlampe. Electr. Techn. Zeitschr., 12, 323-330.

[14] Igawa, N. (1992), Sky luminance distribution data from 12th - 21st May. Private communication.

[15] International Standard Organisation: ISO Standard 15409:2004. (2004), Spatial distribution of daylight - CIE Standard of General Sky, ISO, Geneva.

[16] Karayel, M., Navvab, M., Ne'eman, E. and Selkowitz, S. (1984), Zenith luminance and sky luminance distribution for daylighting calculations. Energy and Building, 6, 2-4, $283-$ 291.

[17] Kähler, K. (1908), Flächenhelligkeit des Himmels and Beleuchtungstärke in Räumen. Meteorol. Zeitschr., 25, 2, 52-57.

[18] Kimball, H. H. and Hand, I. F. (1921), Sky brightness and daylight illumination measurements. Monthly Weather Rev., 49, 9, 481-488.

[19] Kimball, H. H. and Hand, I. F. (1922), Daylight illumination on horizontal, vertical and sloping surfaces. Monthly Weather Rev., 50, 12, 615-628.

[20] Kimball, H. H. (1923), Daylight illumination on horizontal, vertical and sloping surfaces. Transactions of IES (N.Y) 18, 5, 434-474.

[21] Kittler R, Perez R and Darula S. (1998), A set of standard skies characterizing daylight conditions for computer and energy conscious design. Private Report of US-SK grant project, abridged version published by Polygrafia, Bratislava, 1998.

[22] Darula, S., Kittler, R. and Gueymard, CH. (2005), "Reference luminous solar constant and solar luminance for illuminance calculations", Solar Energy 79, 559-565.

[23] Kittler, R., Kocifaj, M. and Darula, S. (2010), The 250 anniversary of daylight science and looking forward. Lighting Res. Technol., 42, 479-486.

[24] Kittler, R., Kocifaj, M. and Darula, S. (2012), Daylight Science and Daylighting Technology. Springer, New York.

[25] Kittler, R. and Darula, S. (2015), The simultaneous occurrence and relationship of sunlight and skylight under standard sky types. Lighting Res Technol., 47, 565-580.

[26] Kobav, M., B. (2006), Uporaba digitalnega fotoaparata s širokokotnim objektivom v funciji merilnika porazdeletve scetlosti neba. Proc. Razsvetljava Conf. Bled, 167-178.

[27] Kobav, M., B., Byzjak, G. and Dumortier, D. (2013), Characterization of sky scanner measurements based on CIE and ISO standard CIE S 011/2003. Lighting Res Technol., 45, 4, 504-512.

[28] Lambert, J. H. (1760), Photometria sive de mensura et gradibus luminis, colorum et umbrae (Photomery for measuring and grading light, colour and shades). Augsburg: Detlefsen. (German translation by E. Anding: Lamberts Fotometrie. Leipzig: Klett Publ., 1892. English translation by D. L. DiLaura: Photometry, or on the measure and gradation of light, colors and shade. New York: Publ. IES Amer., 2001).

[29] Lambert, J. H. (1773), Merkwürdige Eigenschaften der Bahn des Lichte durch die Luft und überhaupt durch verschiedene sphärische und concentrische Mittel. Haude und Spener, Berlin. 
[30] Longmore, J. (1964), The full-field photogrammetric technique in lighting research. The Photographic Journal, 104, 5, 133-141.

[31] Lummer, O. and Brodhun, E. (1889), Ersatz des Photometerfettfleckes durch eine rein optische Vorrichtung. Zeitschr.f. Instrumentenkunde, 9, 23-41.

[32] Marie, F. (1700), Nouvelledécouverte sur la lumiére, pour la mesurer et en compter les degrees. L.Sevestre, Paris.

[33] Maurolyco, F. (1575), Photismi de lumine. Venezia. English translation by Crew, H. The photismi de lumine by Maurolycus. Macmillan, Co., New York 1940.

[34] Middleton, W. E. K. (1942), The "Diffusing Effect" of fog. Journ. Opt. Soc. Amer., 32, 3, 139-143.

[35] Mie, G. (1908), Beiträge zur Optik trüber Medien, speziell kolloidaler Metallösungen. Annalen d. Physik, 25, 377-445.

[36] Moon, P. and Spencer, D. E. (1942), Illumination from a non-uniform sky. Illum. Engineering, 37, 10, 707-725.

[37] Ogiso, S. and Takei, M. (1966), "Ot-scope by Ogiso and Takei": the whole-sky photographic instrument with the orthographic projection. Trans. Of the archit. Institute of Japan, 1, 119-122.

[38] Pleijel, G. (1952), The globoscope, an instrument for the analysis of sunlight and daylight. Byggmastären, 31, 10, 219-224.

[39] Sumec, S., Škoda, J., Krbal, M. and Baxant, P. (2013), Evaluation of illumination using digital photography. Proc. CIE Centenary Conf., Paris, 1208-1215.

[40] Tregenza, P., R. (1987), Subdivision of the sky hemisphere for luminance measurements. Lighting Res. Technol., 19, 1, 13-14.

[41] Valko, P. (1986), Angular distribution of sky radiance and diffuse irradiance on inclined surfaces. Course on physical climatology for solar and wind energy. Intern. Centre for Theoretical Physics, Terste.

[42] Vitruvius, M. P. (13 BC, printed in 1487 AD), De architectura libri decem. Rome. English translation by M. H. Morgan, Vitruvius: The ten books on architecture. Cambridge, Mass. Harvard Univ. Press, 1914 and Dover. N. Y., 1960, also by F. Granger, Vitruvius: Of Architecture, The ten books. Heinemann, London 1970.

[43] Weber, L. (1883), Milchglasphotometer. Wiedemans Annalen der Physik, 20, 326-330.

[44] Weber, L. (1885), Intensitätsmessungen des diffusen Tageslicht. Ann. Der Physik und Chemie, 25, 11, 374-389. 